\title{
Study on the Sustainable Development of Natural Gas Resources in China
}

\author{
Yi Su and Kedong Luo
}

\begin{abstract}
Natural gas as a low carbon, high efficiency, and clean energy plays an important role in many fields such as agriculture, industry, social life, the national economy development and energy structure optimization. However, natural gas is a non-renewable resource. As facing the limitations of its reservation and production and the accelerating expansion of its use, we have to take positive and effective measures to improve the sustainable development of natural gas resources. This paper expounds the definition of sustainable development, respectively analyzes the connotation of sustainable development from its natural attribute, social attribute and economic attribute, and explains the essence of sustainable development. According to the idea of sustainable development, the resource foundation for the sustainable development of natural gas in china is analyzed and problems facing in the sustainable development of natural gas are discussed. Therefore, in order to promote the sustainable development of natural gas in our country, we have to solve the problems we are facing through diverse strategies. Finally, natural gas will play a more important role in the national energy structure, and make a greater contribution to energy-saving, emission reduction, and the development of national economy.
\end{abstract}

Index Terms-Natural gas, sustainable development, resource foundation, energy utilization structure, development strategy.

\section{INTRODUCTION}

Fossil energy resources are abundant, while renewable energy development faces many bottlenecks. Therefore, in the future fossil fuels are still the main engine which supports the world economic development. Natural gas as the fossil energy of low carbon, high efficiency, and clean energy, plays a more and more important role. In recent years, under the situations of the rapid changes in the global geopolitical pattern, natural gas supply and demand change, climate change and environmental pressure, American unconventional gas breakthrough, Japan's nuclear crisis and the new energy economic technical factors, the global degree and dependence to the attention of the natural gas is further pushed up. With natural gas production increasing year by year, the rapid growth of demand for natural gas, as well as worldwide unconventional gas development and utilization, natural gas utilization field will be further expanded, and gas industry will get a fast development in the worldwide [1].

Manuscript received October 13, 2014; revised November 28, 2014.

Yi Su and Kedong Luo are with the PetroChina Planning and Engineering Institute, Beijing 100083, PR China (e-mail: suyi916@petrochina.com.cn, luokedong@petrochina.com.cn).
Since 21st century, the exploitation and utilization of natural gas in China has achieved great development, and the market has entered a period of fast development. Speeding up natural gas utilization, establishing strategic position of natural gas in China's energy system, and promoting the sustainable development of natural gas are of great significance for ensuring China's energy supply and energy security, protecting the ecological environment and improving the energy structure.

\section{The Connotation of Sustainable DeVElopMent}

Sustainable development, refers to while exploring natural, and using natural resources, not only meeting the contemporary's needs of survival, and development, but also not damaging the ability of future generations to meet their needs; ensuring the moderate growth and structure optimization of today's economy, but also maintaining the permanent use of resources and environmental optimization, so that we will achieve an organic coordination between environment and economy, getting an order sustainable development [2].

From natural attributes of sustainable development, it is to seek a kind of optimum ecological system, to support the realization of the ecological integrity and human desire so that the living environment of mankind will continue. That is, sustainable development is not beyond the updating ability of environmental system.

From social attributes of sustainable development, it is to improve the quality of human life under the situation that people's survival does exceed the ecological system's capacity to maintain itself. Therefore, the ultimate goal of the sustainable development is human society, which is to improve the quality of human life, creating a better living environment.

From economic attributes of sustainable development, it is to achieve the maximum net profit of economic development under the premise of maintaining the quality of natural resources and services it provided. In other words, toady's economic development should not reduce the environmental quality and destroy the development of the world natural resource base.

Sustainable development as a new concept of development, its content includes the connotation of the material form, basically also contains a kind of humanistic spirit which means human sustainable development needs the population, resources, environment, economy and society's harmonious development. 


\section{THE FUNDAMENTAL FOR THE SUSTAINABLE} DEVElopMENT OF NATURAL GAS RESOURCES IN CHINA

\section{A. Calculation of Natural Gas Resources in China}

Measurement of natural gas resources in China began from the national key research project "the research and development of coalbed methane research". Scientific research institute of oil exploration and development predicted the coalbed methane resources in 11 major coal bearing basins of China; Former Ministry of Geology and Mineral petroleum geological research institute studied 9 main coalbed methane basins, and the coalbed methane resource was about 17.9 trillion cubic meters (TCM).

According to the dynamic evaluation results of the national oil and gas resources latest released by the ministry of land and resources on January 8, 2014, the geological resource of natural gas in China is 62 trillion cubic meters, which increased by $77 \%$ and $20 \%$ respectively compared with the evaluation results in 2007 and 2010. In recent years, China's gas reserves maintain a high growth and proven geological reserves during 2000 to 2012 increased by 760 billion to 1.33 trillion cubic meters, so the average annual growth is $5.9 \%$. The output average annual growth is more than two digits, increasing from 27 billion cubic meters in 2000 to 107 billion cubic meters in 2012, and the average annual growth is $12 \%$. Natural gas still maintains a high yield in 2013, about 117 billion cubic meters, up $8.6 \%$ from a year earlier.

\section{B. The Distribution of Natural Gas Resources in China}

Our country is rich in natural gas resources, more than $80 \%$ of which mainly distribute in Sichuan, Ordos, Tarim, Qaidam, the South China Sea and the East China Sea. Areas in which the amount of resources is more than 1 trillion cubic meters are Tarim, Sichuan, Erdos, East China Sea, Bohai Bay, Ying Gehai, Qaidam, Junggar etc. Land accounts for about $60 \%$, while sea accounts for about $40 \%$. However, natural gas resources in China are obviously imbalance, most exploration object with characteristics of low porosity, low permeability, deep burial, complex reservoir, high temperature and high pressure formation, which makes China's natural gas distribution have the following features.

The distribution of natural gas resources is not harmonious with economic development. Natural gas resources are mainly concentrated in central western regions of China, while the consumption market is mainly in the eastern region. For example, the top five markets of natural gas consumption in China are Guangdong, Shanghai, Beijing, Jiangsu, Tianjin, accounting for $59.94 \%$ of the national market share, and the top three accounts for $50.33 \%$ of the market share. The imbalance of distribution region makes natural gas resources away from the terminal consumer market. National western development strategy will focus on solving the gas supply in the eastern developed areas and large medium cities, striving for optimal allocation of resources, and realizing the optimal benefits. "Sichuan gas goes to east," "west gas goes to east," and "sea gas goes to land' are the direct embodiment of the strategy.

Natural gas resources are mostly located in areas with poor natural conditions. Resources in desert area, mountainous area, the loess plateau, and sea area account for $26 \%, 25 \%$,
$12 \%$ and $21 \%$ of the total respectively. The average elevation of the Qaidam field is the highest in the world, whose condition is very hard; the Tarim gas field is located in the desert and gobi; the northern of Ordos gas field is desert and grassland; Sichuan gas field is known as one Poem of Li Bai "the road to Shu is harder than to climb to the sky". Natural gas resource in bad loess area, mountain area and desert area accounts for $64 \%$ of the total resources.

Natural gas is buried with complex geological conditions. Gas fields in China are mostly small ones, whose geological structures are complicated, and difficult to explore and develop. 58.39\% of China's onshore natural gas resources are buried in the depth of more than 3500 meters, and low permeability and extra-low permeability reservoir accounts for half of resources. Since 1958 natural gas containing hydrogen sulfide has been found in Sichuan basin for the first time, we have found them in other places such as Bohai bay basin, Ordos basin, Tarim basin and Junggar basin etc. However, at present there are a lot of limitations in studying its formation mechanism and distribution.

\section{Analysis of Natural Gas Consumption Demand in China}

At present our country gas consumption lags behind the world average level, but in recent years with the energy security and environmental protection consciousness rising, there is still great room for growth in natural gas demand [3], [4]. It is expected that in 2014 consumption will reach 186 billion cubic meters, and imports will reach 63 billion cubic meters. In future, the demand for natural gas in China will continue to rise. It is estimated that it is likely to reach 200 billion cubic meters in 2015, 300 billion cubic meters in 2020 , 500 billion cubic meters in 2030 . The gap between supply and demand will also be further expanded (Fig. 1).

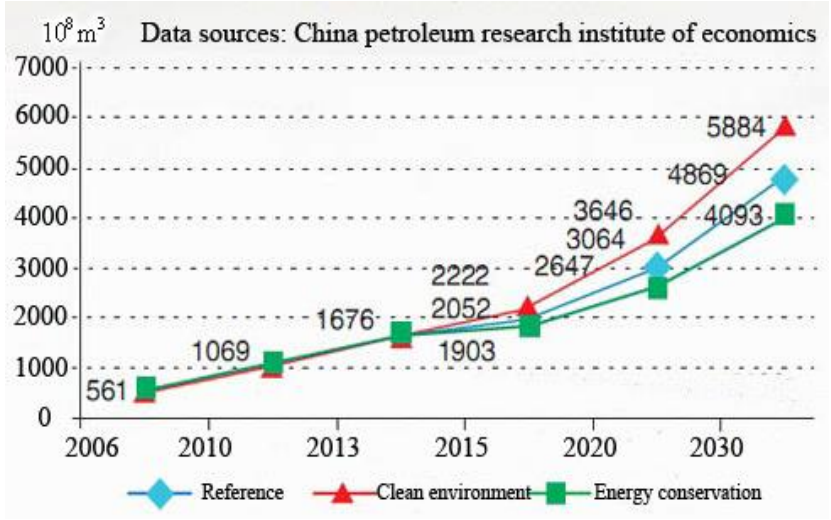

Fig. 1. China's natural gas demand forecasting.

It is expected that in the next 10 years [5], major natural gas consuming regions in China are still to be the southwest, Bohai Bay, Yangtze River Delta and the southeast coast, and the main natural gas consumption fields will concentrate in industry and residents. According to estimation, the natural gas market pattern during the period of "twelfth five-year" will be: $32 \%$ of urban gas, $31 \%$ of industry, $16 \%$ of chemical, and $21 \%$ of power generation. The generator gas proportion in China is still lower than the foreign mature market level. As the rise in price of natural gas, natural gas economy fell slightly in the fields of industry and power generation. 


\section{Problems in the Sustainable DeVelopment of NATURAL GAS IN CHINA}

Both opportunities and challenges remain in the development of China's natural gas industry. First of all, as for the opportunity, with the rapid development of the national economy and the improvement of people's living standard, the demand for natural gas continues to rise, which provides a good opportunity for the rapid development of China's natural gas industry. Secondly, compared with the output growth and the demand for natural gas in China, there is still a wide gap between them. Therefore, the development of natural gas will face the following challenges in the future [6].

\section{A. The Contradiction between Supply and Demand of Natural Gas}

With the rapid development of China's economy, the improvement of people's living standard, and the pressure of environmental protection, natural gas industry in China is facing a good opportunity. As gas accumulation theory and exploration technique progress, it is expected that the development of natural gas industry in China still continues to maintain a rapid developing momentum in quite a long period of time. According to the IEA (International Energy Agency) prediction of 2012, China's natural gas production will break through 200 billion cubic meters in 2025, and will exceed 300 billion cubic meters in 2035 (seen in Fig. 2). However, the growth of natural gas production is far lower than its demand growth. Therefore, according to the current rate of consumption, natural gas needs will reach 310 billion cubic meters in 2020, and the external dependency will be up to $40 \%$.

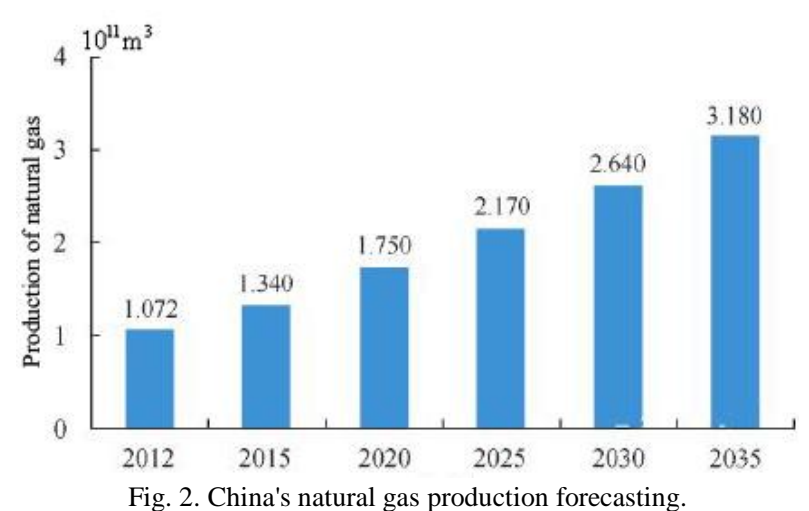

\section{B. The Ratio of Natural Gas in Primary Energy Is Much Lower than the World Average}

In recent years, with the development of low carbon energy structure, the pace of China's natural gas utilization is accelerating and the ratio of natural gas in primary energy is rising. In 2003 natural gas in primary energy structure only accounted for $2.5 \%$, and has risen to $5.2 \%$ in 2012 . The oil ratio is greatly reducing; the coal ratio rose quietly; the renewable energy ratio has greatly improved. According to the plan, the ratio of natural gas in primary energy will reach $7.5 \%$ in 2015 .

However, compared with the world's average level, there is still a big gap in China. In the world's primary energy consumption structure, natural gas accounts for $24 \%$ on average, which remains relatively stable more than 10 years. Oil and nuclear power presents a declining trend, while coal shows a rising trend because of its great resources, and progress of clean utilization technology.

\section{Natural Gas Utilization Efficiency Is Low, and the Energy Consumption Structure Is Not Reasonable}

Most of the existing natural gas utilization projects in China have problems of low use efficiency. Natural gas in city is mainly used to give off heats to meet the needs of the residents' life. At present, China's natural gas infrastructure and use technology are relatively backward so that we cannot make full use of its combustion energy. The same problems happened in natural gas chemical industry, whose natural gas use efficiency lagged behind developed countries a lot. Natural gas as an industrial fuel directly burns in the boiler. As a result, a lot of heat from burning will be wasted in flue gas. Compared with industrial fuel, natural gas used in central air conditioner has a relatively higher efficiency. But as for its use efficiency in central air conditioner, the thermodynamic efficiency is still low. The efficiency of power generation with larger-scale gas turbine has reached $40 \%$ while the efficiency of power generation with combination of gas turbine and steam turbine may reach $60 \%$.

\section{The Existing Management System Restrict the Development and Utilization of Natural Gas}

Natural gas industry is a highly monopoly industry, in which resource development, network transmission and sales are controlled by one enterprise. Due to highly natural monopoly, there is lack of fair competition. Meanwhile, because of natural gas price set by the government, it limits the mechanism of market price discovery and formation by itself. The system in which natural gas supply is determined by natural gas producing enterprise while its price is set by the government causes an uncoordinated contradiction between the supplier and the consumer. On the one hand, the local government requires large amount of low price of natural gas. On the other hand, natural gas producing enterprise wants to raise the price of natural gas and hope to supply its natural gas to those enterprises that have strong price affordability.

\section{StRategies Releasing the Sustainable DEVELOPMENT OF NATURAL GaS IN CHINA}

At present, under the drive of environmental protection and national energy policy orientation, the actual growth rate of China's natural gas demand may be faster than the IEA's forecast. It is expected that the average growth rate of demand will reach $15 \%$ in the next 5 years. In 2015, the demand will reach 200 billion cubic meters, while at the same time the domestic production in China can only provide 120 billion cubic meters. Therefore, in order to promote the sustainable development of natural gas in China, we should take all kinds of ways to solve the problems. The details are as follows [7], [8].

\section{A. Strengthen the Development of Unconventional Natural Gas}

Shale gas is a special kind of unconventional natural gas, 
and is mainly located in mudstone, high carbon, silty mudstone and sandwich rock. Shale gas is very abundant in the world, and its total resource is about 456 trillion cubic meters, equivalent to the sum of coal-bed methane and tight gas. It mainly distributes in North America, central Asia, China, the Middle East, North Africa, Latin America and other regions. Shale gas has the following characteristics: (1) its distribution range is wide, and mainly in Marine strata; (2) its sedimentary thickness is big, generally 300 to 500 meters, and a single layer thickness is greater than 50 meters; (3) its organic matter content is over $2 \%$, and the maturity (Ro) is between 1.4 and 3.0 ; (4) its mining life is long, generally 30 to 50 years, and some can reach 80 to 100 years. Recoverable shale gas in the world is listed in the Table I.

TABLE I: RECOVERABLE SHALE GAS IN THE WORLD

\begin{tabular}{llll}
\hline \hline Countries & {$[\mathrm{TCM}]$} & Countries & {$[\mathrm{TCM}]$} \\
\hline China & 36.8 & French & 5.09 \\
American & 24.39 & Norwegian & 2.35 \\
Argentina & 21.9 & Chile & 1.81 \\
Mexico & 19.27 & India & 1.78 \\
South Africa & 13.73 & Paraguay & 1.75 \\
Australia & 11.21 & Pakistan & 1.44 \\
Canada & 10.98 & Bolivia & 1.36 \\
\hline \hline
\end{tabular}

Shale gas reservoir is widely distributed in China, whose two main types are marine and continent. Marine deposits are the main body, which always distributes in the South, the North and the Tarim basin of Xinjiang; Continental deposits are mainly distributed in the Songliao, Erdos, Bohai Bay, Junggar, Turpan Hami basin and its periphery. With good shale gas accumulation conditions, there is high potential to explore shale gas in these regions. Especially for marine shale its distribution area is wide; its thickness is large; its organic matter is abundant and its maturity is moderate. It is estimated that marine shale gas in the three main regions accounts for $70 \%$ of the total. According to IEA's forecasts, recoverable resources of shale gas in China reaches 1275 trillion cubic feet, equal to 36 trillion cubic meters. According to the ministry of land and resources survey, shale gas in land is 134.42 trillion cubic meters, and its recoverable resource potential is 25.08 trillion cubic meters (excluding the Qinghai and Tibet areas), which is equal to that of conventional natural gas.

\section{B. Improve the Use Structure of Natural Gas in China}

In recent years, our country has built several natural gas pipelines, which cover most of the country, to further promote the consumption of natural gas in China. With the rapid development of natural gas industry, great changes have taken place in our country natural gas utilization structure and meanwhile its structure is optimized constantly, but compared with the world present structure, there is a lot of differences. Before 2000, China's natural gas consumption is mainly in the fields of chemical and industry, accounting for nearly $80 \%$. By 2012, the city gas has become the largest gas field, accounting for $39 \%$ while industrial and chemical gas ratio from $41 \%$ and $37 \%$ in 2000 decreased to $29 \%$ and $18 \%$ respectively, and meanwhile power generation rise fast, up from $4 \%$ to $18 \%$. However, there are still a lot of irrationalities in natural gas use, so we have to take measures to make some corresponding adjustments. The basic direction is to continue to develop the city gas and pay more attention to the fields of high efficiency, high yield and low emission. In addition, we should continue to develop natural gas used as industrial fuel, vigorously develop natural gas cogeneration, and appropriately develop natural gas chemical industry, to ensure the sustainable development of natural gas industry in China.

\section{Strengthen the Construction of Natural Gas Pipeline and Other Infrastructure}

With the rapid development and utilization of natural gas, natural gas pipeline and other infrastructure still cannot meet the needs of the market, which becomes the bottleneck restricting the sustainable development of natural gas. Speeding up and encouraging infrastructure construction such as natural gas pipeline, underground gas storage is a significant means to ensure the rapid development of natural gas market. Peak shaving facilities such as underground gas storage is always the bottleneck of China's natural gas development. As natural gas consumption increased dramatically, load pressure will be increasingly large, so peak shaving facilities such as underground gas storage will become the focus of future construction, and should be comprehensively advanced.

\section{Improve the Pricing Mechanism of Natural Gas in China}

In order to promote the sustainable development of natural gas, we need to develop a natural gas price system suitable for the market economy. The present price system based on the government should gradually transit to the price system in which market regulation is basic and administrative intervention is auxiliary. We should establish a price formation mechanism mainly based on market supply and demand to make the price of natural gas in China gradually in line with international standards, really reflecting the value of natural gas commodity. As a result, we can eventually form a fully market-oriented pricing mechanism, to ensure that the natural gas industry will be in a healthy and benign development track. At the same time, we have to strengthen the government's regulation of price at price, improve the enthusiasm of natural gas producing enterprise, and guide all society to rationally use gas and save gas.

\section{CONCLUSION}

Natural gas as a kind of low carbon, high efficiency and clean energy plays a crucial role in many areas such as agriculture, industry and social life, and is an essential factor in the national economic development and the energy structure optimization. Facing the limitations of reserves and production and the acceleration of natural gas utilization, some positive and effective measures must be taken in our country to promote the sustainable development of natural gas. In the future, with the progress of unconventional natural gas exploration, the improvement of natural gas pipeline and other infrastructure construction, and the joint efforts of all governments, gas supply companies and downstream users, 
the natural gas market in China will present a good developing momentum in which consumption will continue to grow rapidly, utilization region will be gradually all over the country and using direction will be continuously optimized. In a word, natural gas will play a more important role in the national energy structure, and make a greater contribution to energy conservation and emission reduction

\section{REFERENCES}

[1] X. C. Shi, "Some thoughts about sustainable development of the natural gas industry," Natural Gas Industry, vol. 29, pp.13-16, 2009.

[2] M. S. Gao, "The research of gas resource characteristics and the sustainable development in the northeastern Sichuan basin," Ph.D. dissertation, Chengdu University of Technology, China, pp. 111-114, 2007.

[3] N. Li, Q. Y. Ma, and J. P. Guo, "Sustainable development and utilization of natural gas in China," Journal of Anshan University of Science and Technology, vol. 26, 2003.

[4] H. Sun and L. Shan, "2012 development trend and 2013 prospects in China's natural gas industry development," International Petroleum Economy, vol. 6, pp. 21-26, 2013.

[5] W. Li, Y. Yang, and X. J. Liu, "Current situation and development trend of natural gas consumption in China," Sino-Global Energy, vol. 5, pp. 8-12, 2010.

[6] K. X. Xue, Y. X. Hu, and G. S. Pan, "Development situation of natural gas industry in China," Gas \& Heat, vol. 31, pp. 32-37, 2011.

[7] F. D. Zhang, "The study on China natural gas sustainable development strategy," Ph.D. dissertation, China University of Geosciences, China, 2005.

[8] J. P. Yin and H. Huang, "The supply and demand of natural gas in China and its future consumption policies," Reformation \& Strategy, vol. 26, pp. 26-29, 2010.

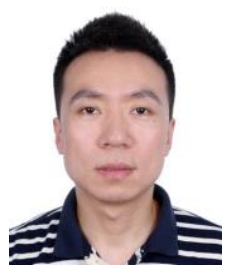

Yi Su was born in Tianshui, Gansu Province, China on August 21, 1983. He successfully completed his B.Sc. degree in vehicle engineering and master's degree in mechanics and electronics engineering from Beijing University of Aeronautics and Astronautics, China in 2006 and 2009 respectively. He received his $\mathrm{PhD}$ degrees in mechanics and electronics engineering from University of Science and Technology Beijing, China 2013.

Now he is pursuing his postdoctoral study under the school of business at RenMin University of China from 2013 and works as an intermediate engineer in PetroChina Planning and Engineering Institute where he mainly engages in the research of ERP (enterprise resource planning) system of natural gas and pipeline.

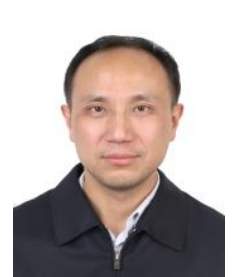

Kedong Luo was born in China on September 4 1976. Luo successfully completed his B.Sc. degree in computer science from Tsinghua University, China in 1995. Then he received his master degree and $\mathrm{PhD}$ degree in computer science from Tsinghua University, China in 2004.

After his graduation, he started to work in PetroChina Planning and Engineering Institute and mainly focused his study on enterprise information system designing and construction, as well as information technology research and development. He was appointed as the vice director of Information Center in 2006. At present, he has been serving as the director of Information Center of Natural Gas and Pipeline since 2012. Meanwhile, he is a senior technical expert of China National Petroleum Corporation.

In recent years, as the project director and principal member, Dr. Luo has won more than 10 technical prizes, among which 5 prizes are provincial or ministry level. In 2006, Dr. Luo was given the title of "Informationization Advanced Individual in Group Company". In 2011, Dr. Luo has won the prize "National Petrochemical Industry Integration Advanced Individual". 